\title{
Osteosarcoma: About a Case
}

\author{
*Lázaro Robaina Ruíz \\ Department of orthopedics, Universidad de Santiago Guayaquil, Spain
}

Submission: June 27, 2017; Published: July 12, 2017

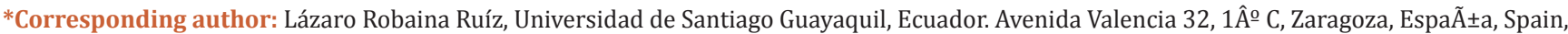
Email: lazaro_robaina@yahoo.es

\begin{abstract}
K.C.P, a thirty-six-year-old mixed-race woman, referred to outpatient trauma clinic by a clinical oncology department of the Guayaquil Hospital for a right-sided tumor of the right forearm for a two-year bone tumor.
\end{abstract}

Keywords: Osteosarcoma

\section{Case Report}

K.C.P, a thirty-six-year-old mixed-race woman, referred to outpatient trauma clinic by a clinical oncology department of the Guayaquil Hospital for a right-sided tumor of the right forearm for a two-year bone tumor. In an external consultation of traumatology, the patient tells us that it takes approximately two years with pain and increase of volume of the limb, that the limb increases by days and that has become greater in the last seven months, also reports that it has been going to several doctors looking for a solution.

\section{Discussion}

We present K.C.P, female, thirty-six-year-old mestiza, referred for tumor in right forearm, at the physical examination, we observed an increase in the severe volume of the carpus and a distal third and a third of the right forearm, with a rounded and multilobular fixed tumor, with a hard, solid, painful palpation, associated with collateral circulation, the tumor extending from the line Articulation of the right carpus to about $14.3 \mathrm{~cm}$ of the forearm, with a maximum circular perimeter of $38.4 \mathrm{~cm}$ in the carpus and distal forearm.

In the consultation, we indicate preoperative protocol to perform tumor biopsy, in addition examinations of general hematology, biochemistry, acid and alkaline phosphatase, calcium, phosphorus, Rx, Bone scintigraphy; T.A.C of thorax for tumor staging. In the Antero posterior and lateral Rx of the right forearm, we obtain very suggestive images of Osteosarcoma, with radiolucid images, radiodenses or both, ill defined in their contour and are associated with bone destruction of both cortical and medullary bone. In the complementary ones, we found Hemoglobin in 9, $8 \mathrm{~g} / \mathrm{L}$, phosphatase in $270 \mathrm{U} / \mathrm{L}$, the bone scintigram, the T.A.C of the thorax and the negative abdomen and the examinations carried out evidence non-metastatic disease.

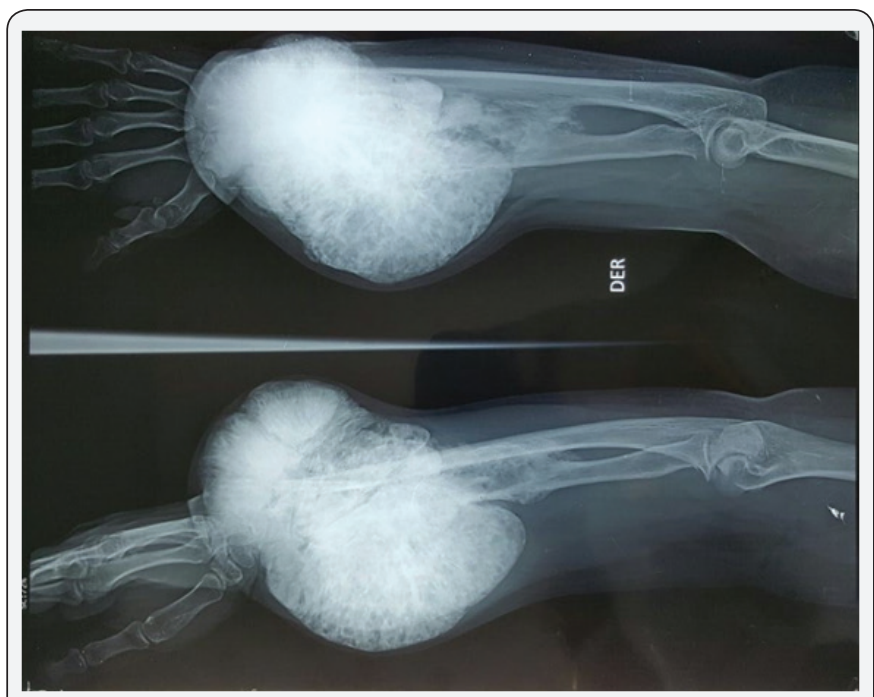

Figure 1: Initial and pre-operative biopsy images: Rx AP and right forearm lateral.

Tumor bone biopsy is performed, simultaneous samples are sent to pathological anatomy laboratories at Guayaquil Hospital and SOLCA Hospital. (Cancer Society) Two weeks later we received a report from pathologists diagnosed with Osteosarcoma. The case is discussed in Medical Staff integrated by Traumatology, Anesthesiology and Clinical Oncology, where surgical staging is considered between IA - IB, Intra - Extracompartimental bone and muscle of origin, with low degree, based on Enneking 1980. It is agreed by unanimous 


\section{Orthopedics and Rheumatology Open Access Journal}

consensus Medical staff perform amputation of the limb at the supra-condyle level of right humerus associated with postsurgical chemotherapy (Figure 1).

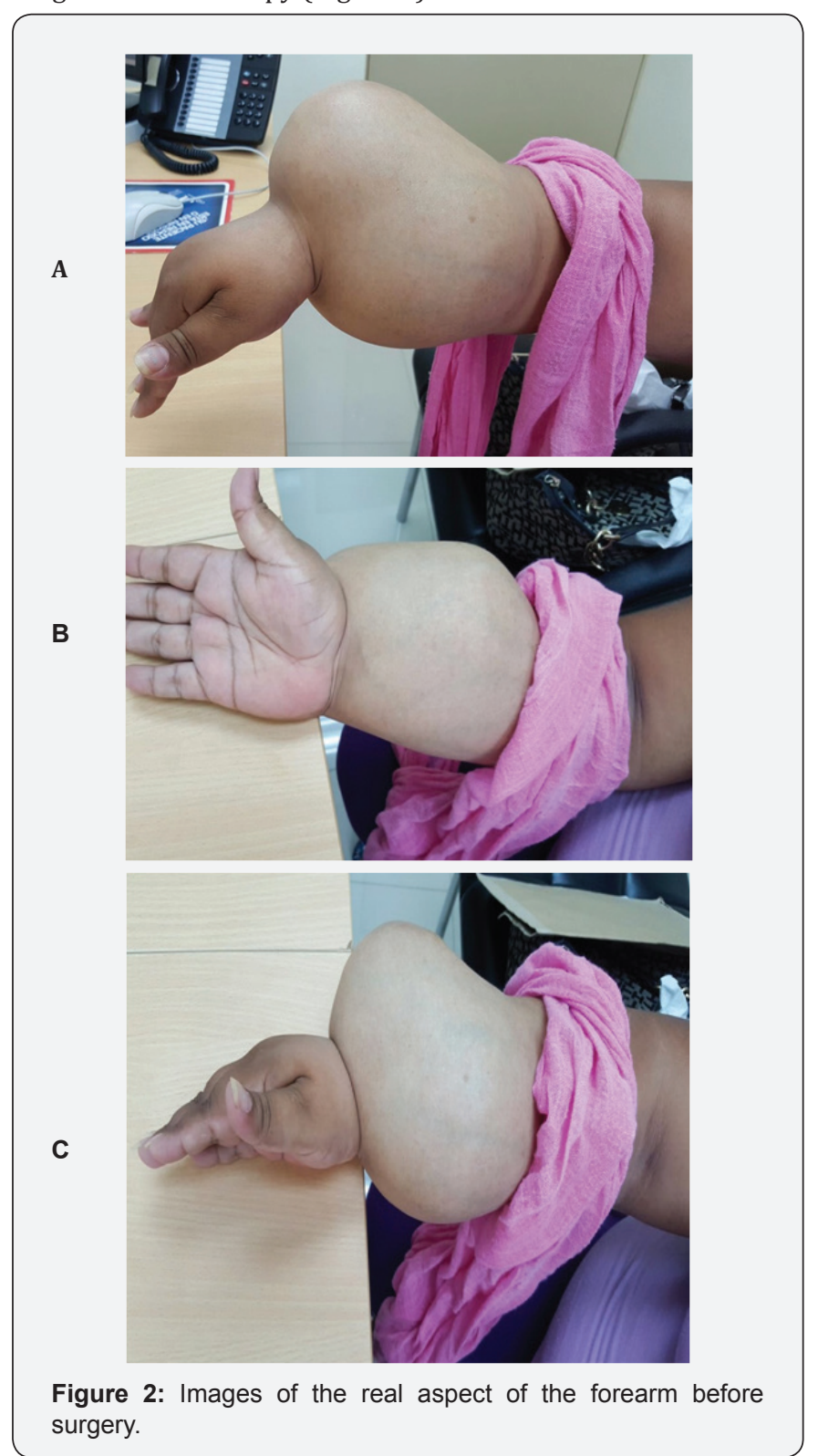

Figure 2: Images of the real aspect of the forearm before surgery.
The patient and family member is informed of amputation of the limb at the supra-condyle level of the right humerus; Patient and family accept surgical proposal and sign informed consent for surgery Preoperative control and evaluation by anesthesiology, internal medicine and cardiology with evaluation suitable for surgery. We programmed the surgery and performed amputation of the upper extremity at the supra condyle level of the right humerus. The surgical resection based on Enneking 1980, for our case, was extensive because of the magnitude of the tumor that covered the carpi, the metaphysis and much of the diaphysis of both bones of the right forearm (Figure 2).

The patient is hospitalized for 48 hours at the post-surgical period. Interconsultation is performed with hospital oncologists for evaluation of neoadjuvant or post-surgical chemotherapy and follow-up by external consultation. The patient and relatives confess their full well-being and appreciation for the care and treatment received.

\section{Conclusion}

We performed amputation of the upper extremity at the supra condyle level of the right humerus. The surgical resection based on Enneking 1980, for our case, was extensive because of the magnitude of the tumor that covered the carpi, the metaphysis and much of the diaphysis of both bones of the right forearm. Interconsultation is performed with hospital oncologists for assessment of neoadjuvant or post-surgical chemotherapy and follow-up by external consultation.

\section{Conflicts of Interest}

There are no conflicts of interest in this article.

\author{
Your next submission with Juniper Publishers \\ will reach you the below assets \\ - Quality Editorial service \\ - Swift Peer Review \\ - Reprints availability \\ - E-prints Service \\ - Manuscript Podcast for convenient understanding \\ - Global attainment for your research \\ - Manuscript accessibility in different formats \\ ( Pdf, E-pub, Full Text, Audio) \\ - Unceasing customer service
}

Track the below URL for one-step submission https://juniperpublishers.com/online-submission.php 